\title{
El realismo dialéctico en la historia de Antonio García Nosa
}

Prólogo a El realismo dialéctico enla historia. La crisis del marxismo como filosofía de interpretación de la historia. Hacia el nuevo orden del hombre. De Antonio García Nosa

La obra de Antonio García Nosa El realismo dialéctico en la historia ya de por sí presenta un título principal sugerente pues intenta indicar - tras el controvertido concepto de realismo que ha sido interpretado de las formas más diversas desde el pensamiento escolástico hasta la contemporaneidad - una postura que identifica a este destacado pensador colombiano con distanciamientos críticos del pensamiento especulativo e idealista. Lo cual se aprecia aun más al observar los subtítulos de la misma, entre ellos, La crisis del marxismo como filosofía de interpretación de la historia, que de algún modo orienta mejor al lector sobre el objeto propiamente del libro.

No se trata de un análisis histórico filosófico de la dialéctica desde la antigüedad hasta nuestros días, aunque su conocimiento lo presupone y 
de cierta forma aborda. Al mismo tiempo el enunciado Hacia el nuevo orden del hombre parece indicar uno de los objetivos del libro, ya que las reflexiones antropológicas que contiene conducen a plantear la posibilidad de la construcción de un nuevo orden distante y distinto del impuesto por las relaciones socioeconómicas capitalistas.

Ahora bien, si el concepto de realismo ocupa un lugar privilegiado en esta obra de Antonio García no es por circunstancias fortuitas sino porque el análisis de la realidad social, económica, política y cultural de su entorno estuvo siempre presente en su pupila insomne. De ahí que con acierto Hugo Caicedo haya sostenido que "la extensa, sólida, original y útil obra de Antonio García no es exclusivamente producto de la reflexión la creación teóricas, sino que esta ratificada y confrontada con el conocimiento directo y crítico de la real realidad." (Caicedo, 1987, p. 32).

Una de las expresas intenciones de García es demostrar que nada escapa a la concepción dialéctica del desarrollo, ni siquiera el mismo pensamiento dialéctico que no concebirá como un constructo a priori sino como la expresión sublimada de las contradicciones necesarias que impulsar el devenir universal y conducen la eterna superación de la realidad histórica.

Desde un primer momento se esmera en destacar que "La dialéctica ha sido no sólo una filosofía inconformista -en relación con la tendencia histórica del pensamiento hacia diversas formas de absolutismo conceptual-, sino una filosofía revolucionaria, en cuanto se esfuerza por explicar las transformaciones contradictorias de la vida y el proceso de continua mutación de las cosas, así como también por comprender las leyes de las relaciones y de la interinfluencia, en el campo de la naturaleza o en el campo de la vida humana" (García, p. 5).

De este modo enfatiza en el plano epistemológico aquella desacertada tendencia que acomoda el pensamiento a los conceptos absolutos por una parte, pero a la vez revela el contenido ideológico que subyace tras el conservadurismo de dichos absolutismos y eclecticismos. Al insistir que el carácter revolucionario de la dialéctica va más allá de su dimensión ontológica y epistemológica para proyectarse en su significado sociopolítico insinuando el carácter práctico que se desprende de su asunción.

Un elemento consustancial a todos los análisis de García fue siempre su postura crítica contra cualquier tipo de dogma y de fosilización de las verdades, "Pero nuestra primera obligación -de crítica no de apostasía es no aceptar para 
ninguna de estas tesis la naturaleza de verdad revelada, que no necesita demostraciones. Hemos llegado a un punto en el que toda verdad necesita demostrarse" (García, 1995, p. 180). En modo alguno debe interpretarse tal aseveración en el sentido tradicional del empirismo o del verificacionismo neopositivista, tan distante al andamiaje teórico que estructura todo su pensamiento.

Tal vez uno de los méritos que se insinúan desde las primeras páginas de esta obra es considerar el carácter histórico universal de la dialéctica y por tanto su validez para el estudio y renovación de las ideas y la praxis del socialismo, pero en especial del anquilosamiento de algunas de las interpretaciones del pensamiento marxista. Esto se observa cuando sostiene "Pero se equivocan quienes piensan que esa filosofía es revolucionaria sólo para un tipo de sociedades y para unos ciertos aspectos de la vida: lo es siempre y no sólo para la naturaleza sino para la sociedad y el hombre, concebidos como criaturas históricas, esto es como sujetos y objetos de un incesante proceso de creación y recreación" (García, 2006. p. 23.).

Uno de los defectos más usuales de los análisis que se efectuaban por esa misma época en que García escribía este texto, por parte del denominado marxismo soviético — así caracterizado por Merleau Ponty inicialmente y luego acuñado por Herbert Marcuse, quien elogiaría la obra del pensador colombiano- era considerar que el instrumentario crítico del marxismo y de la dialéctica materialista solo era apropiado para otras sociedades distintas a la del "socialismo realmente existente" (Breznev) y para otras corrientes filosóficas distintas al marxismo. Precisamente uno de los auténticos aportes de este libro - con independencia del mayor o menor índice de originalidad- ${ }^{135}$ es plantear que el método dialéctico era

135 "En la historia universal una filosofía ha sido original y auténtica no cuando ha planteado simplemente ideas nuevas, sino cuando estas se han correspondido con las exigencias históricas de su momento en los diferentes planos, sociopolítico, económico, ideológico y científico' Guadarrama, P. Humanismo en el pensamiento latinoamericano. Editorial Ciencias Sociales. La Habana. 2001. p.7; segunda edición Universidad Pedagógica y Tecnológica de Colombia, Tunja. 2002, p. 38; Tercera edición: Universidad Nacional de Loja-Universidad de Cuenca-Casa de la Cultura Ecuatoriana. Loja. 2006. p.7 
imprescindible para estudiar al mismo marxismo ${ }^{136}$ y los diferentes ensayos y teorías socialistas hasta ese momento desarrollados.

A la par enfrentándose a las visiones teleológicas y mesiánicas del socialismo y el comunismo prevalecientes en esa época posterior a la Segunda Guerra Mundial, en la que el socialismo de un modo u otro se fue imponiendo en unos países como los de Europa Oriental y en otros emergía por fermentos propios como en al caso de China, Vietnam, Corea o Cuba; García observó con escrutador ojo crítico el anquilosamiento que se le intentaba inútilmente imponer al análisis de las nuevas experiencias socialistas. A su juicio, "Toda sociedad es un término y un camino de tránsito, un punto de llegada y de partida: no podemos, entonces, anclarnos en concepciones que -teórica o prácticamente- niegan ese carácter abierto y dinámico de la transformación social y se petrifican en los marcos inmutables y perfectos de la Tierra Prometida" (García, 2006, p.6). Y precisamente explica las causas de la deserción de teóricos e ideólogos comunistas como el caso del yugoeslavo Milovan Djilas, quien formuló el concepto de la burguesía roja y autor de La sociedad imperfecta (Djilas, 1970) entre otros, al que se pudiera agregar el del peruano Eudocio Rabines con su obra La gran estafa, ante el mito racionalista de la sociedad socialista perfecta.

Mientras la izquierda tradicional, y en particular los partidos comunistas, simplemente intentaban resolver este problema considerándolos de un plumazo como simples desertores, revisionistas, agentes del enemigo; García intentaba y lograba de algún modo hurgar en las causas que producían aquellos impresionantes virajes ideológicos.

En ocasiones anteriores había planteado que "la ortodoxia marxista ha sustituido el pensamiento dialéctico por el dogmatismo, el análisis por el absolutismo crítico" (García, 2006, p. 26) y valoraba las nefastas consecuencias

136 Rubén Jaramillo en una entrevista luego de la lectura del manuscrito de El realismo dialéctico en la historia de Antonio García comentaba: "porque hay cosas muy acertadas, por ejemplo esto de aplicarle los principios dialécticos al propio fundamento dialéctico es lo que dice Korsch. Karl Korsch dice, al marxismo hay que aplicarle el marxismo; entonces, al aplicarle el marxismo al marxismo, deja de ser una doctrina absoluta, sacrosanta, porque se historiza; es lo mismo que decía Gramsci: el marxismo es un estoicismo radical. Esto está muy bien, entonces es bueno decirlo, es bueno que la gente se entere que García estaba pensando lo mismo que Korsch". Jaramillo Velez, R. Entrevista realizada por Luis Emiro Valencia. 15 de marzo de 1990. 
prácticas que esta postura teórica había traído para el movimiento revolucionario internacional.

Con objetividad impresionante denuncia que "Si las clases o fuerzas dirigentes norteamericanas no están inclinadas a aplicar la filosofía dialéctica en el estudio de su propia economía capitalista -para descubrir y aplicar las leyes de su transformación revolucionaria-, los grupos dirigentes soviéticos tampoco han estado inclinados a aplicar la filosofía dialéctica al estudio y comprensión de la realidad en que viven, de los fenómenos que generan -voluntaria o involuntariamente- y de las concepciones que mantienen frente a los nuevos hechos" (García, 2006, pp. 26-27). A lo que podríamos agregar algo peor al apreciar que después del derrumbe de la URSS y del socialismo en Europa Oriental, tal reticencia de utilizar el propio marxismo y la dialéctica materialista para explicar las causas de semejante desastre se ha mantenido.

En la misma época en que García fundamentaba sus críticas reflexiones sobre el experimento soviético castrado por el estalinismo, otro revolucionario controvertido y también excomulgado por la iglesia soviética del marxismo, del mismo modo que anteriormente había ocurrido con José Carlos Mariátegui (1985, p. 126), ${ }^{137}$ por parte de los que se autoconsideraban poseedores exclusivos del marxómetro oficial, ${ }^{138}$ - para medir la mayor o menor cantidad de ingredientes marxistas que había en alguien-, en este caso Ernesto Guevara quien se refería al escolasticismo en que se había convertido al marxismo y el terrible daño que causaban los ladrillos

137 Mariátegui se enfrentó a las interpretaciones dogmáticas del marxismo que efectuaba Bujarin en su catecismo de "marxismo descarnado y esquelético" Mariátegui, J.C. Defensa del marxismo. Colección Obras Completas. Amauta. Lima. 1985. T.V. p. 126.

138 García al valorar a Mariátegui consideró que: "aunque internacionalista y ortodoxo, su obra está lejos del marxismo dogmático de los comunistas oficiales de América, tan estéril para el análisis y la creación política y tan íntimamente emparentado haciendo abstracción de las diferencias formales con el esquematismo simplista de los liberales precomptianos". García, A. "Interpretación de la ciencia colombiana y latinoamericana”. Manuscrito inédito \# 21, Círculo de Estudios Económico Sociales Antonio García. Bogotá. p. 33. 
soviéticos $^{139}$ al referirse a los manuales de marxismo-leninismo producidos entonces en la URSS.

Esto significa que García se ubica también en ese aspecto en la tendencia más auténtica del pensamiento marxista latinoamericano de su época que trataba de rescatar el arma de la crítica tan consustancial al pensamiento originario de Marx y tan ajeno a todo dogmatismo. Así se revela en estas palabras:

Las exigencias del poder -allí donde se han instalado poderosas dictaduras burocráticas como en la Unión Soviética dentro de los esquemas estratégicos del stalinismo- han ido determinando el cercenamiento y la asfixia del pensamiento crítico, en aras de los "dogmas oficiales". Se ha llegado así, por negaciones, a la congelación o reducción de la dialéctica a un aparato formal a través del cual se ha regresado al absolutismo crítico, a la mitificación de ciertos procesos y a la sustitución del análisis por la retórica. La congelación es, doctrinariamente, el abandono de la postura dialéctica a cambio de una posición absolutista y dogmática. (García, 2006, p.7).

De tal manera, García desentrañaba la nefasta articulación entre autocracia política y cercenamiento del episteme como ha sucedido históricamente en otros momentos de la historia en que científicos y filósofos se han visto censurados por inquisitorios mecanismos represivos.

En tal sentido García, consciente o inconscientemente, confluiría con las ideas de Rosa Luxemburgo, cuyo pensamiento evidentemente manejo y referenció, según las cuales no puede haber socialismo sin democracia, ni democracia sin socialismo. Solo un socialismo de profundo contenido

139 Expresión de la autenticidad y del carácter heterodoxo del pensamiento marxista del Che fue su crítica al totalitarismo y al dogmatismo. Esta postura se puso de manifiesto en muchas ocasiones y especialmente cuando en 1965 le escribe a Armando Hart: "En este largo período de vacaciones le metí la nariz a la filosofía, cosa que hace tiempo pensaba hacer. Me encontré con la primera dificultad: en Cuba no hay nada publicado, si excluimos los ladrillos soviéticos, que tienen el inconveniente de no dejarte pensar; ya el partido lo hizo por ti y tu debes digerir." Guevara, E. "Carta a Armando Hart Dávalos" 4 de diciembre de 1965. Contracorriente. Una revista cubana de pensamiento. La Habana. Julio-Septiembre de 1997. p. 144. 
humanista y democrático que superara el individualismo capitalista ${ }^{140}$ para el pensador colombiano sería terreno propicio para que las ciencias y la filosofía desplegaran sin preocupaciones el vuelo de la creatividad crítica. Esas razones le conducían a plantear:

Pero si las batallas que ha tenido que librar la filosofía dialéctica en el pasado han estado orientadas, fundamentalmente, contra el absolutismo religioso, parece que en el presente se tendrán que enderezar contra el absolutismo político. Y no bastará con que los hombres se llamen dialécticos para qué piensen dialécticamente, sino que no estén comprometidos en la oficialización de una verdad, porque entonces de verdad rica, viva, fluida, abierta se transformará inevitablemente en una verdad de piedra. (García, 2006, p.8).

Sin duda, si la vida le hubiera alcanzado para apreciar el derrumbe del modelo eurosoviético de socialismo hubiera lamentado seguramente también la pérdida de muchas de las conquistas sociales y económicas que se habían logrado en aquellos países, pero a la vez habría corroborado muchas de sus observaciones críticas sobre la forma en que había sido aplastado el espíritu crítico no solo del marxismo en particular, sino de la filosofía y de la ciencia en general al ser controlados por mecanismos eminentemente ideológicos.

Pero su análisis no se limitaba a valorar ese fenómeno de coacción del pensamiento crítico en el caso del marxismo, sino que iba mucho más allá, pues a partir de una valoración integral de este fenómeno extraía algunas conclusiones que conformarían los pilares de su propia interpretación filosófica de la historia, como puede apreciarse cuando plantea:

Los conflictos históricos sirven para provocar el vigoroso afloramiento de doctrinas nuevas -que no sólo plasman nuevas ideologías, sino que canalizan las energías espirituales represadas- pero luego su poder catalítico obra en sentido de congelación y encerramiento.

140 "Pero además, el otro problema contemporáneo es el de dar una conformación racional a la sociedad, lo que equivale a decir que el individualismo humanista debe transformarse en socialismo humanista"' García, A. Dialéctica de la democracia. p. 101. 
El florecimiento teórico e ideológico se efectúa por lo general en la primera época, cuando debe aceptar y responder el reto de la oposición a unas fuerzas sociales y a unas formas culturales dominantes: a la inversa de lo que ocurre a nivel de las personas físicas, es una posibilidad de la 'primera época', la de la heterodoxia, su madurez y la afirmación del espíritu crítico. Pero una vez que la doctrina, los cuerpos de doctrina, se incorporan a la vida social como ortodoxia, van afirmándose sus aspectos negativos y marchitándose sus facultades críticas. (García, 2006, p.8).

Aquí se plasma el profundo pensamiento dialéctico de García que revela la intríngulis no solo de lo sucedido en la involución de ciertas interpretaciones del marxismo sino en otros momentos significativos a la historia del pensamiento universal.

García trató por todos los medios de salvar la naturaleza renovadora de la dialéctica al considerar que "La filosofía dialéctica significa, históricamente, una constante e irreductible lucha contra el intento de congelar la vida en pétreas categorías aparentemente universales" (García, 2006, p.9). Pero tal vez lo más significativo haya sido el hecho de destacar el carácter eminentemente práctico que implica una asunción dialéctica del mundo ya que, según él, "La dialéctica le ha servido al hombre no sólo como un método de pensamiento crítico, sino como un medio de participación en la transformación de su propio universo; en esta facultad impulsiva, en esta condición dinámica de una filosofía que no sólo enseña cómo existen los hechos sino cómo pueden ser modificados, radica su fuerza revolucionaria, su energía y su vitalismo" (García, 2006, p. 9).

No debe obviarse que su consideración de la historia de la dialéctica está permeada del tradicional enfoque eurocéntrico que ignora el desarrollo de la filosofía oriental y los análisis dialécticos que también estuvieron presentes en aquellas culturas, incluyendo las amerindias.

Precisamente una de las más agudas autocríticas suyas estaba dirigida a la falta de originalidad que apreciaba en el pensamiento latinoamericano en todas sus expresiones y el mimetismo que había cercenado la capacidad 
creativa de ideas propias (García, 1953, p. 8). ${ }^{141}$ Por lo que constituían un desafío la necesidad de engendrarlas ajustadas al contexto histórico de nuestros países, en otro trabajo sostendría: "Uno de los más difundidos mitos de las Ciencias Sociales consiste en la creencia de que la teoría científico-social es absolutamente universal y que su validez desborda el marco de los espacios culturales y de los procesos históricos" (García, 1972, p. 1). De ahí que se cuestionase también la capacidad y efectividad de aquellas producciones teóricas emergidas en torres de marfil académicas y desvinculadas de la experiencia vital que ofrece la realidad sociopolítica y cultural de nuestros pueblos (García, 1988, p. 1). ${ }^{142}$ Su obra intelectual precisamente se planteaba la tarea de la construcción teórica propia, la cual sin dudas, con los indispensables desaciertos que acompañan a todo genuino creador, supo lograr.

Para él, desde la antigüedad se ha desplegado una permanente lucha, ya que "el hombre trata de fijar su propio sitio y su propio papel en la tierra" (García, 2006, p. 10), de ahí que considere a la Revolución Francesa y la Revolución Rusa como asaltos históricos de este en busca de liberación social y económica que a su vez presuponen emancipación del pensamiento. En tal sentido establece una adecuada correlación dialéctica entre los procesos emancipadores del pensamiento y los de plano político y socioeconómico. No los ve como estancos separados sino dos momentos de una misma totalidad concreta que deviene y se supera constantemente con los

141 "Todos somos importadores de principios: cristianos y ateos, liberales y antiliberales, socialistas y comunistas. Hasta los fundamentos ideológicos de nuestra fe o nuestra falta de fe en Dios, no nos pertenecen. Nosotros nunca hemos sostenido la necesidad de que alguien deba sacar sus principios de la nada. En rigor de verdad, no existen 'ideas propias' - en el comprometedor sentido de que hayan sido inventadas por uno- sino "ideas aplicadas a las cosas propias". García, A. "El comunismo y la contrarrevolución en Colombia" en García, A. La rebelión de los pueblos débiles. Fondo Socialista de Publicaciones Tomás Uribe Márquez. Bogotá. 1953. p.8.

142 "Para quienes piensan que los hombres de universidad -tan honda y largamente ligados a ella como yo, por vocación y por afecto a las nuevas generaciones- elaboran sus conocimientos emparedados en un gabinete, ha de resultarles inusitada la orientación de mi actividad científica. La universidad puede, seguramente recluirse para ordenar su pensamiento, pero ha de volcarse sobre los cuatro horizontes del suelo del hombre para elaborarlo." García, A. Planificación municipal. Universidad Distrital Francisco José de Caldas. Bogotá. 1988. p. 1. 
indispensables momentos zigzagueantes y de retrocesos parciales comunes a todo tipo de desarrollo.

Sin embargo, García diferenciaba adecuadamente ambos planos pues sabía que en el de la acción práctico revolucionaria y muy especialmente cuando se trataba de luchar por la realización de ideales socialistas o comunistas (García, 1978, p. 60), ${ }^{143}$ no solo eran necesarios el componente teórico y el manejo racional de la realidad sociopolítica; también había que saber desplegar aquellos elementos vitales, volitivos, emotivos e irracionales en cierta forma, que los genuinos líderes políticos sabían con arte y carisma manejar, utilizando la experiencia histórica de otros procesos revolucionarios o transformativos en los que la adecuada utilización de la psicología, la oratoria y sobre todo la capacidad de crear convicciones en correspondencia con la claridad y factibilidad de sus programas sociopolíticos. Para el:

Los principios dialécticos rigen también para el pensamiento dialéctico: su desarrollo en la conflictiva historia contemporánea es un desarrollo contradictorio, de continuas negaciones. Y como no se trata de filosofías inactivas, quietistas, que retengan el conocimiento en un plano de abstracciones y concepciones puras -sino de filosofías activistas y que incitan simultáneamente al conocer y al hacerla confrontación, la lucha, las va haciendo intolerantes y dogmáticas, es decir, va erosionando y arrasando sus fundamentos dialécticos. No hay nada más anti-dialéctico que partir de un a priori absoluto. (García, 1978, p.11).

143 "La trascendencia radical de la sociedad comunista -o más exactamente, de la imagen diseñada por los grandes ideólogos y profetas, de Marx a Lenin y a Mao Tsetung no consiste en su entera racionalidad, en la rigurosa posibilidad histórica de un esquema fraguado por la vía de la negación absoluta de los valores que estructuran la sociedad capitalista (propiedad, clases, Estado, derecho, familia, cultura, conciencia), sino en la capacidad de desencadenar y movilizar la voluntad y el esfuerzo de las élites revolucionarias y de los pueblos. En esto consiste la fuerza secreta del pueblo ruso o del pueblo chino en la reciente historia de sus transformaciones y en esto radica uno de los medios más dinámicos de la estrategia de desarrollo. En la experiencia histórica de América Latina ha sido decisivo el papel desempeñado por el objetivo finalista, el señalamiento de lo que una sociedad quiere ser". García, A. La estructura del atraso en América Latina. Hacia teoría latinamericana del desarrollo. El Ateneo, Pedro Garcia. S.A. Buenos Aires. 1978. p. 60. 
Antonio García se percató de las concesiones que la interpretación dogmática del marxismo propiciaron incluso al idealismo, como también sucedió en el caso del llamado marxismo occidental según plantea Perry Anderson (1985, p. 72) al caer en la misma trampa que el propio Engels había criticado con la construcción de los sistemas filosóficos cerrados (Engels, 1972, p. 265); como sucedió con la formulación del llamado materialismo dialéctico, término que al parecer Antonio García en cierto modo acepta como válido (García, 2006, p. 11), ${ }^{144}$ y del cual ni Marx ni su compañero tuvieron la más mínima idea, aunque formularon las tesis de lo que sí consideraron como dialéctica científica (Marx, 1972, p. 38), en contraposición a la dialéctica idealista hegeliana. Por esa razón García plantea "nada hay más parecido a una Iglesia que un sistema cerrado de pensamiento que da un cuadro acabado del tiempo y del espacio" (García, 2006, p. 11), de lo cual concluye que "La más grande equivocación de las corrientes ortodoxas y oficiales del marxismo consiste en creer que puede presentarse como un cuadro acabado de exégesis del universo y que todo el papel de la dialéctica consiste en retocarlo o en ornamentarlo" (García, 2006, p. 11).

Concebir la dialéctica como un aparato totalmente engrasado y dispuesto a ser aplicado a cualquier circunstancia de modo apriorístico y exógeno en lugar de, como sugería Lenin, redescubrir la dialéctica en la realidad histórica, concreta, específica y particular (Lenin, 1963, p. 243), ese fue el gran error cometido por el marxismo oficial cultivado por muchos de los filósofos soviéticos especialmente a partir del estalinismo, aun cuando algunos no cayeran en esa trampa.

Uno de los graves problemas que a juicio del pensador colombiano condujeron a que tomara fuerza en el marxismo tal tipo de enfoque fue el determinismo economicista, que como bien es conocido fue finalmente tema de autocrítica por parte de Engels. El hecho de intentar buscar una causa de todas las causas dio lugar al predominio de una visión economicista, especialmente en el caso de algunos discípulos de Marx autodenominados marxistas, término este que el propio Marx rechazó para que no lo confundieran con

144 “'El pensamiento dialéctico no sólo ha evolucionado negando Marx a Hegel, sino negándose a sí mismo: no ha bastado que el idealismo dialéctico hubiese sido negado por el materialismo dialéctico, sino que el propio Hegel niega a Hegel y Marx niega a Marx'”. Garcia, A. Realismo dialéctico en la historia p. 11. 
aquellos que hiperbolizaban sus teorías. García se cuestionaba, ¿qué es, dentro de la historia, la idea de Hegel, sino una versión de la causa causarum?, y ¿qué es la consagración de la estructura económica como un superfactor de la sociedad y de la historia, sino un regreso al absolutismo conceptual y a la aceptación de la idea metafísica de la causa causarum? (García, 2006, p.11).

Si bien son justificables algunas de sus observaciones críticas por parte del pensador colombiano a la extrapolación del papel del factor económico que se derivó de algunas formulaciones del propio Marx y también de Engels, tal parece que García no les perdonara semejante error al haber propiciado con este desliz trascendental una especie de nueva metafísica del absoluto económico. Sin embargo, es evidente que se desprende, al menos en estas observaciones críticas, una postura más inclinada hacia la teoría multifactorial del desarrollo social que al reconocimiento de la real significación del papel del móvil económico en el desarrollo social, político y cultural, tan consustancial a la concepción materialista de la historia elaborada por aquellos y madurada tempranamente, independientemente de la aceptación o no del corte epistemológico althuseriano (Althuser, 1966), en el primer capítulo de La ideología alemana.

Quizás estudios más amplios y profundos del pensamiento económico y filosófico de Antonio García permitan una mejor valoración de sus ideas al respecto, las cuales, como en el caso de cualquier pensador, evolucionaron y depende mucho del momento en que se analicen a fin de evitar las mismas formulaciones absolutas sobre su pensamiento, que él mismo criticara.

Uno de los principales objetivos de ese libro de García lo plasma diáfanamente cuando expresa, "Esto es, justamente, lo que intento plantear en este ensayo: el examen dialéctico de las formas de aplicación en la historia del método dialéctico, en el campo del idealismo y en el del materialismo. El idealismo dialéctico -inspirado en el idealismo trascendental- no podía entender la vida subestimando los hechos reales; pero el materialismo dialéctico -inspirado en muchos prejuicios del materialismo mecanicista- tampoco, si negaba a las ideas, a las fuerzas morales y psicológicas, una presencia real en la historia humana. Una idea incorporada a la vida del hombre es tan real como una fuerza que no pueda proyectarse al plano de los hechos" (García, 2006, p.13). Todo indica que estas consideraciones están referidas fundamentalmente a las formulaciones comúnmente divulgadas por la manualística del dia-mat y no propiamente a las ideas de Marx o de Engels al respecto. 
Aunque no haga referencia a las mismas en dicho texto, es de suponer que el pensador colombiano conociese las reflexiones de aquellos en su primera obra conjunta La sagrada familia, referidas al carácter invencible que adoptan las ideas cuanto toman plena conciencia en las masas populares (Marx y Engels, 1965, p. 132). Así como también debió conocer otras valoraciones engelsianas sobre aquellas "formas ideológicas que vuelan más alto que las nubes como la filosofía o la religión", pero que se comportan como una extraordinaria fuerza real y motora, como sucedió en el caso de las ideas de la Reforma Luterana encarnadas materialmente en el movimiento revolucionario campesino dirigido por Tomas Münzer en Alemania (Engels, 1967).

García aspira a diferenciar debidamente la concepción idealista de la materialista de la historia aunque percatándose también de los posibles puntos de confluencia entre ambas si se interpone algún tipo de apriorismo axiológico en el análisis de los hechos históricos. Por esa razón enfatiza que "El materialismo histórico, es en términos esenciales, una transposición radical del idealismo histórico, en el sentido de que su punto de partida es un esquema mental del mundo, una clasificación racional en categorías, un sistema de ponderación y de valores, por medio de los cuales se emprende la audaz tarea de ordenar la historia, a posteriori" (García, 2006, p. 13).

El hecho efectivo de que la interpretación de la historia propugnada por el marxismo no se efectúe desde una perspectiva apriorística no lo exime del posible análisis forzado de la realidad histórica a partir de esquemas preconcebidos o transpuestos a realidades históricas diferentes. Contra ese error se previno el propio Marx cuando le escribía a Anennkov que aquellos historiadores que transponían su esquema de las formaciones económico-sociales, elaborado a partir de la historia europea a otras latitudes y pretendían así universalizarlo, le hacían demasiado honor pero a la vez demasiado daño y escarnio, pues él no había planteado eso y tal vez por esa misma razón Marx no quería ser confundido con los autodenominados historiadores marxistas.

García comprende muy bien que una filosofía, independiente de sus mayores o menores ingredientes de verdad, puede funcionar como ideología, o como"filosofía oficial" como sucedió en el caso del marxismo en Rusia y en China y convertirse en un poderoso instrumento de transformación revolucionaria. Por tal motivo, se cuestiona, con razón, y la vez trata de explicar por qué el marxismo se convirtió en la filosofía que mayor trascendencia 
tuvo en los movimientos de liberación nacional, anticoloniales y antiimperialistas que se produjeron principalmente en América Latina, África y Asia en el pasado siglo. Así formula la cuestión, “¿Cómo no creer que si el marxismo -como materialismo histórico- es la filosofía que inspiró y guió las dos más profundas revoluciones del siglo xx, no pueda ser la filosofía oficial de todas las revoluciones?" (García, 2006, p. 14). Una simple inferencia lógica conduce a pensar que del mismo modo que el liberalismo y el positivismo sui generis (Guadarrama, 2004) inspiraron las transformaciones independentistas y revolucionarias del siglo xix latinoamericano, del mismo modo que lo hizo en Europa o en Asia, como las Reformas Meiji en el Japón, nada tenía de extraño que inspirara tan heterogéneos movimientos sociales y revolucionarios en el convulso pasado siglo.

De acuerdo con el pensador colombiano, "Es tan importante históricamente la revolución -como único medio de romper los estados de represamiento social- que explica suficientemente la vigencia práctica del marxismo como filosofía de la acción, no obstante que no podría hablarse de su plena vigencia teórica en el campo de interpretación de la historia" (García, 2006, p.14). De esta afirmación se pueden derivar tres conclusiones parciales:

1. Al menos en el momento en que escribe este ensayo admite el papel significativo de las revoluciones sociales en el sentido que Marx las había concebido como locomotoras de la historia (Marx, 1982, p. 166) y de este modo contribuye a disipar dudas ante aquellos que han considerado en sentido general las ideas sociopolíticas de García como reformistas.

2. Al considerar al "marxismo como filosofía de la acción", no toma en consideración la especificidad no simplemente terminológica en cuanto a la denominación, ya que su conceptualización como filosofía de la praxis tanto en la tradición de Antonio Labriola y Antonio Gramsci, como en la de la escuela de Zagreb y de Adolfo Sánchez Vázquez (Sánchez, 1975) enfatiza la significación de la práctica en sus diversas determinaciones y que distancian al marxismo tanto de la concepción de la acción del idealismo subjetivo de Fichte, como de las diferentes versiones de la acción que se asumen en Max Weber, Talcott Parsons y Robert Merton, entre otros, así como en sus interpretaciones pragmatistas. 
3. Finalmente, sostiene una afirmación muy general y descalificadora del marxismo al considerar "que no podría hablarse de su plena vigencia teórica en el campo de interpretación de la historia" que implica incluso contradecir algunos planteamientos propios de García en relación a la validez de determinados elementos básicos de la teoría marxista y no tomar en consideración adecuada las diferentes interpretaciones y aportes teóricos que existen de la misma que han dado lugar incluso a abiertas contradicciones entre corrientes, tendencias, discípulos, continuadores, y otros, o lo que el Che gustaba en denominar "los marxismos".

Por otra parte, el pensador colombiano formula una tesis muy crítica del manejo ideológico que se hizo del marxismo en los países socialistas sin establecer diferencias adecuadas entre los posibles contenidos científicos (Castro Gómez, 1999, p. 76) ${ }^{145}$ que puedan contener diferentes ideologías, entre ellas el marxismo, cuando opera como tal. Su afirmación de que "Las ideologías posiblemente tienen una mayor duración cuando se han convertido -como en el caso del liberalismo político y del marxismo como filosofía históricaen simples supersticiones" (García, 2006, p.14), independientemente del mayor o menor elemento de verdad en cuanto a la mayor supervivencia de las ideologías que las filosofías, presupone una inadecuada equiparación que no toma en cuenta la especificidad de esos diferentes procesos de ideologización ni los diferentes grados de contenidos epistémicos existentes en el liberalismo y en el marxismo, aun cuando este, como hemos sostenido anteriormente, no debemos asumirlo como un corpus monolítico, sino como una teoría con componentes científicos, filosóficos y también ideológicos que a diferencia de otras filosofías culposamente manifiesta su proyección ideológica (Guadarrama, 2002, 86). ${ }^{146}$ Cuando éste se revela en el plano

145 “...la palabra ideología no es peyorativa (...)un concepto puede ser al mismo tiempo ideológico y también correcto y verdadero". Jameson, F. "Apuntes sobre la globalización como problema filosófico". En Pensar en los intersticios. Teoría y práctica de la crítica postcolonial. Castro Gómez, S. y otros Editores. Pensar. Pontificia Universidad Javeriana. Bogotá, 1999. p. 76.

146 "El marxismo no oculta su intención de hacer desaparecer a la burguesía, a los terratenientes y a cualquier manifestación de poder económico enajenante que engendre explotación del hombre por el hombre. Por supuesto que tal desaparición se refiere 
científico, especialmente en el estudio del desarrollo de capitalismo premonopolista por parte de Marx, Engels, Plejanov, Labriola, Bebel, entre otros, o en su etapa imperialista con Lenin, Rosa Luxemburgo, Trotsky, Gramsci, y demás, o en sus manifestaciones más recientes por parte de otras personalidades de la tradición marxista, se ha comportado como cualquier otra construcción científica con un núcleo duro (Lakatos, 1983) de teorías y algunos cinturones periféricos moldeables, relativos, circunstanciales e históricos (Guadarrama, 1998, p.244). ${ }^{147}$

Más allá de cualquier posible desacierto en cuanto a la valoración de la función ideológica del marxismo, lo importante es la intención del pensador colombiano en esta obra de rescatar la dialéctica de aquellas deformaciones que ha sido objeto por parte de algunos de sus cultivadores desde el controvertido marxismo ortodoxo. Tal intención se revela en este planteamiento: "El materialismo dialéctico no es la forma final de la dialéctica, sino la negación del idealismo dialéctico: estamos a las puertas de una nueva negación, la que se afirma en el concepto de una dialéctica no-dogmática, que no parta de ningún a priori y no quiera sentar que las Estaciones de Tránsito son la Tierra Prometida" (García, 2006, p. 14). Pero llama poderosamente la atención que en ese rescate desprejuiciado a que convoca García, haga referencia elogiosa al tan criticado estudio de Engels sobre la dialéctica de

como clase o poder y no a su eliminación como individuos. La franqueza del discurso marxista en este aspecto ha sido su principal fortaleza ideológica, en tanto que para los que se oponen a estas intenciones ha sido su mayor debilidad. Por el contrario, los defensores del liberalismo o del neoliberalismo en la actualidad, entre otros, por lo regular se asumen como representantes de los intereses de toda la sociedad, sin excluir a ninguna clase o grupo social menos favorecido, que lógicamente no pretenden extinguir, sino a reproducir permanentemente, como condición básica de su propio bienestar". Guadarrama, P. "El lugar del componente ideológico en la filosofía y en el pensamiento político.” En Guadarrama, P. Filosofía y Sociedad. (Tomo I y II) (Director de colectivo de autores). Editorial Félix Varela. La Habana. 2000.p. 86.

147 "Toda teoría social se ve afectada permanentemente por los altibajos de la historia. Ninguna concepción sobre el desarrollo de la sociedad ha podido transitar sin tropiezos por el complicado sendero de la historia y el marxismo no es, en ese sentido, una excepción." Guadarrama, P. "El núcleo duro de la teoría marxista y su afectación por la crisis del socialismo". Islas. Revista de la Universidad Central "Marta Abreu de Las Villas. Santa Clara. N. 108. Mayo-agosto 1994.p. 16. Guadarrama, P. Humanismo, marxismo y postmodernidad. Editorial Ciencias Sociales. La Habana. 1998. p. 244. 
la naturaleza por su presunta ontologización de este método y también que considere como aportes de la dialéctica los estudios multifactoriales de Max Weber sobre el desarrollo social.

Tales afirmaciones son expresión de la independencia intelectual de García (Sabogal, 2004, p. 251) ${ }^{148}$ que le permitía acudir de forma electiva, como ha caracterizado a los más destacados representantes de la producción del pensamiento latinoamericano, a diferencia del eclecticismo, a asumir dialécticamente los mejores frutos de la cultura universal sin sectarismos ideologizantes.

Por supuesto que tal independencia intelectual y postura heterodoxa dentro del pensamiento marxista motivaría las críticas provenientes de aquellos sectores que se consideraban exclusivos propietarios del patrimonio de Marx. De manera que García se vio como otros intelectuales latinoamericanos de la época atacado por dos francos: la derecha tradicional que con razón lo calificaba como un marxista y un socialista; en tanto la izquierda tradicional, injustamente a nuestro juicio, lo consideraba como no suficientemente marxista ni totalmente socialista (Misas, 1883, p. 219). ${ }^{149}$

Al finalizar el primer capítulo de su obra al que denominó La dialéctica del pensamiento dialéctico concluye magistralmente:

Estamos a las puertas de esta concepción abierta, realista, dialéctica de la dialéctica. Esa concepción podrá pretender -nada más y nada menos-, el restablecimiento del método dialéctico, salvándolo del absolutismo del lado idealista o del lado materialista. Esto es: poniendo de nuevo el método sobre sus pies. Dialéctica abierta vs. Dialécticas

148 "El más importante de tales aportes, a mi modo de ver, es su invitación a pensar la realidad latinoamericana desde América Latina, a la luz de un pensamiento propio". Sabogal, J. El pensamiento económico de Antonio García. Paradigma de independencia intelectual. Editorial Plaza y Janés. Bogotá. 2004. p. 251.

149 "Antonio García, cuya producción intelectual se remonta a los años cuarenta, con trabajos sobre estructura agraria económica, clases y poderes políticos. Textos que no fueron bien acogidos en su momento, en los medios que se reclamaban del marxismo, debido a la heterodoxia del autor que contrastaba con el rígido dogmatismo de los cuadros del partido comunista, dominantes en los medios socialistas hasta inicios de la década de los sesenta". Misas, G. "El marxismo y las investigaciones económicas en Colombia”. En Fals Borda, O, Molina, G, Fajardo, D y otros. El marxismo en Colombia. Universidad Nacional de Colombia. Bogotá. 1883. p. 219 
cerradas. Afirmación de la dialéctica en sus principios dinámicos Vs. afirmación de la dialéctica en sus principios estáticos. Prevalencia de la interrelación, de los principios de mutua y recíproca dependencia Vs. Prevalencia de los factores estructurales, de los super-factores, de la causa de las causas. (García, 2006, p.15).

Su aspiración en este trabajo era salvar a la dialéctica con la dialéctica misma y para ese fin reclamaba recuperar su espíritu originario crítico, abierto, desprejuiciado, superador de cualquier tipo de dogma incluso el que llegue a hipostasiar la propia dialéctica.

García se planteaba el rescate de la dialéctica no por el simple hecho de hiperbolizar un método en detrimento de otro, sino de salvaguardar la historia de tergiversaciones y de orientaciones nefastas. Su verdadera intención era contribuir a la reconstrucción humanista y socialista de la historia y para ese fin veía en la dialéctica un instrumento insustituible.

Por tal motivo expresaba claramente su interés por una adecuada comprensión dialéctica de la historia cuando planteaba:

La fundamental tarea histórica de la dialéctica ha sido la revaluación y vitalización de la historia. No importa cuales hayan sido las adquisiciones individuales y los errores de sus grandes maestros, en los campos idealista y materialista: lo cierto es que mediante el enfoque dialéctico de la historia no sólo aprendió el hombre a comprender, críticamente, las formas y móviles de desarrollo de la historia -a través de un amplio y vital concepto de contradicciones, de acciones y de reacciones, de tesis, de antítesis- sino a comprenderla como un proceso. Desde este punto de vista, el hombre aprende a conquistar la más importante de las facultades de autoconocimiento como ser social: la que da unidad a su vida histórica. Toda la moderna aspiración a un Nuevo Humanismo -lucha por el Hombre Total, por la Sociedad Total, por la integración de la especie humana, del hombre y de toda persona- se encuentra contenida en los esquemas de Hegel y más, ampliamente, más coherente y orgánicamente en Marx, en cuanto sus concepciones históricas -limitadas por la perspectiva idealista o materialista-, buscan, en última instancia, un hombre íntegro y una historia íntegra (García, 2006, p. 16). 
En verdad resulta innegable que tanto los pensadores idealistas como materialista que han redescubierto la dialéctica en la realidad, como aconsejaba Lenin, independientemente de la postura ontológica que los ha caracterizado, han contribuido de un modo u otro a una mejor comprensión del mundo, pues en definitiva el "idealismo inteligente" siempre ha estado más cerca del "materialismo inteligente" (léase marxismo), que éste del materialismo torpe y vulgar.

El hecho de que el pensador colombiano atisbara esa proximidad constituye un mérito significativo, dada la época en que formula sus ideas cuando generalmente prevalecía en las interpretaciones del marxismo oficial una versión algo dicotómica y maniquea respecto al idealismo y el materialismo que eran apreciados más bien como dos equipos de un partido de fútbol en el que cada cual parecía que sólo se plantearan asestar un gol en la portería contraria y jamás reconocer el mérito del contrincante. García considera que "El error inicial tanto del idealismo como del materialismo histórico -que hasta cierto punto han ido rebajando la calidad y profundidad de sus investigaciones en la determinación del proceso de la historia - ha sido la de considerar que sólo una perspectiva dominante idealista o materialista, -que parta del espíritu o de la tendencia humana a subsistir- puede realizar y garantizar la unidad de ese proceso histórico" (García, 2006, p.16).

Por supuesto que la consideración del materialismo filosófico simplemente como "la tendencia humana a subsistir" resulta desacertada o limitada a las formas tradicionalmente reduccionistas del materialismo, pero más allá de esta consideración lo que él justamente se plantea es un enjuiciamiento crítico de aquellas posturas que descalifican absolutamente los contenidos racionales que poseen tesis filosóficas antagónicas en lugar de justipreciar al menos algunos de sus valores y argumentos racionalmente fundados.

La intención de su comprensión holística de la historia está orientada hacia un mejor autoconocimiento por parte del ser humano de su condición a fin de perfeccionarla. Independientemente que su lenguaje, se torna por momentos algo abstracto en la búsqueda del "Hombre Total" y de la "Sociedad Total", que le otorga ciertos aires especulativos, tales formulaciones no son más que expresiones de su proyección marxista de lograr el perfeccionamiento humano en una sociedad de tal dimensión en la que el "humanismo práctico" y el "humanismo real" abandonen su tonalidad 
feuerbachiana y se constituyan en aproximaciones, como sugiriera Marx, de lo ideal a lo real para que lo real se aproxime más a lo ideal.

García aspira a salvar tanto a Hegel como a Marx de las interpretaciones forzadas y unilaterales de la historia, efectuadas por algunos de sus discípulos, e insiste en la visión holística de ambos y en la riqueza del enfoque que supere las perspectivas parciales. Por eso insiste en que se logre cada vez más una interpretación de la historia en que múltiples perspectivas se complementen. A su juicio, "La adopción del criterio físico de adoptar un ángulo de enfoque de la historia como si se tratara de un puesto de observación de un mar, de una carretera o de un río, no puede conducir sino a esquemas planos o lineales del proceso histórico. El único método de restablecer la profundidad, la vitalidad, la variedad de dimensiones de la historia, es el de multiplicar las perspectivas" (García, 2006, p. 17).

En tal sentido, intenta recuperar la tradición desarrollada por la dialéctica, especialmente en sus formulaciones en el pensamiento renacentista y moderno (Bruno, Spinoza, Rousseu, Kant, Hegel, Marx, entre otros) que presupone la infinita consideración multifacética del objeto vista en todas sus relaciones diversas con otros fenómenos y procesos que los determinan y condicionan. El vuelo filosófico que toma el pensamiento de García aparentemente lo distancia de sus usuales investigaciones económicas, geográficas, históricas, y demás, pero en verdad lo que hacen es acercarlo a una mejor comprensión esencial de las determinaciones de la historia y por tanto de sus manifestaciones concretas.

No fue esta la primera vez que el enfoque dialéctico y holístico afloraba en los análisis de García. Fueron múltiples las ocasiones cuando se puso de manifiesto, en particular cuando se planteaba la tarea no sólo del trabajo académico o el enfoque teórico sino cuando trataba de formular un programa para la acción política que se orientara con tareas específicas hacia la construcción de Una vía socialista para Colombia, ocasión propicia para que dicho enfoque se revelase y expresase su sentido práctico al plantear que "Los criterios enunciados se inspiran en una concepción orgánica y totalista de la sociedad y del hombre, de la democracia y de la cultura. En esto consiste su fundamentación filosófica y humanista" (García, 1977, p. 54).

En ocasiones su distanciamiento crítico ante Hegel y Marx no le facilitan una mirada diferenciadora del modo en que ambos se movieron en la historia con el instrumento de la dialéctica y le condujeron a enjuiciar, 
a nuestro juicio erróneamente, a este último al considerar que "Marx no siempre fue un afortunado y consecuente marxista" (García, 2006, p. 17) afirmación esta muy discutible pues depende de lo que se entienda por tal. O incluso planteamientos algo más rotundos y contradictorios, por no decir equivocados, como este: "Marx no siempre era un correcto marxista, sino que tampoco lo era en la fundamentación teórica de su perspectiva" (García, 2006, p. 19). Tales planteamientos desconciertan, en cierta medida, cuando se comparan con ideas extraordinariamente elogiosas que aparecen en esta misma obra como considerar que "en su obra histórica Marx sabe eludir los escollos del fatalismo con una verdadera maestría dialéctica" (García, 2006, p. 43). Así como en otro momento destaca que "La aplicación que Marx hace del método dialéctico al análisis del desarrollo del capitalismo en su ambiente clásico -en 'El Capital', Inglaterra- debe considerarse como ejemplar" (García, 2006, p. 37).

En fin, fueron múltiples las ocasiones en que se expresaba la profunda admiración de Antonio García por la obra teórica y también por la praxis militante de Marx, pero a la vez fueron varias las ocasiones en que sostenía que "el error esencial de Marx: el que lo lleva a negar en la práctica el método dialéctico que acepta en la teoría" (García, 2006, p. 37), está dado por su "sistema absolutista de pensamiento. Es allí donde reside, por exceso de filosofismo o por exceso de economismo -por haber vertido a la historia un principio absoluto de la filosofía materialista o por haber sistematizado universalmente las adquisiciones hechas en la historia económica- el error esencial de Marx" (García, 2006, p.37). Tal vez este sea uno de los aspectos más controvertibles de esta obra de Antonio García que demandan un análisis mucho profundo y analítico. Este hecho demuestra que estamos en presencia de una obra de rigor teórico y no de simple divulgación o exposición simplificadora. Se trata de un ensayo filosófico que, como todo trabajo auténtico de esa índole, demanda coautoría crítica del lector para en acercamientos y distanciamientos crear su propia visión realista de la dialéctica de la historia.

La gran ventaja que tiene este pensador colombiano que incursiona en el terreno de lo que las clasificaciones convencionales pudieran considerar como propio de la filosofía de la historia es que, a diferencia de los tradicionales filósofos de la historia, en lugar de construir especulativos sistemas absolutos — nada más ajeno a sus pretensiones— se da a la tarea de filosofar 
sobre la dialéctica real de la historia porque antes incursionó en la historia real de Colombia y de Latinoamérica como experimentado investigador en el terreno de la economía, la planificación municipal y territorial, la historia de los movimientos políticos y sociales, entre otros, pero a la vez como luchador social.

Se trata de alguien que no ha descendido de las nubes filosóficas para tratar de "aplicar" de manera a priori un esquema abstracto a la realidad, sino que a partir de su condición especial de relevante investigador de las ciencias sociales sobre problemas concretos de Colombia y Latinoamérica podía permitirse el lujo de redescubrir la dialéctica en la historia real misma y de ese modo podía contribuir al enriquecimiento de la dialéctica y del propio marxismo despojado de todo fetiche ${ }^{150}$ como también sugería el controvertido marxista mejicano José Revueltas.

La lucha de García contra todo tipo de dogmatismo, empezando por el religioso lo había conducido a innumerables polémicas (García, 1995, pp. IX-X), ${ }^{151}$ nada de extraño tenía que polemizara con quienes habían hecho de la dialéctica una especie de varita mágica que resolviera el más mínimo entuerto.

A fin de rescatar los valores contenidos en el enfoque dialéctico de la realidad y en particular de la historia, García se opuso a cualquier forma de utilización del escolástico principi autoritatis que tanto daño habían hecho a su desarrollo y enriquecimiento cuando se habían endiosado algunos pensadores que más habían contribuido al perfeccionamiento de su condición epistémica y metodológica. Por eso, desde inicio de los años cincuenta había expresado, al respecto con honestidad, su postura que lo distanciaba

150 "No debemos esperar de nadie, sino de nosotros mismos: pensar, escribir, luchar, con audacia, despojados de todo fetiche, (el subrayado es nuestro P. G.) de todo dogmatismo, no importa al punto en que lleguemos" Revueltas, J. Carta a su hija Andrea Revueltas. (1971) en Guadarrama, P. Director de colectivo de autores. Despojados de todo fetiche. La autenticidad del pensamiento marxista en América Latina. Bogotá. UNINCCA. 1999.p. 421.

151 “Por la misma época (1954) se publica El cristianismo en la teoría y la práctica, que recoge la polémica entre Antonio García y el padre Mario Revollo, Director del Catolicismo". Rugeles, C y H. Caicedo. "Palabras al lector". García, A. De la rebelión a la organización de los pueblos débiles". Humanismo y Sociedad. Ltda. Bogotá. 1995. p. IX-X. 
de cualquier tipo de personalismo filosófico cuando escribía "Si la filosofía dialéctica sirve para descubrir los procesos, las leyes de transformación de la sociedad, debe abandonar el arsenal de dogmas que se haya cómodamente alojada, para reiniciar su obra de creación y descubrimiento. Por eso no creo en ninguna filosofía dialéctica que se amarre, indisolublemente, las adquisiciones de personas así sean tan importantes como Hegel o Marx" (García, 1988, p. 78). Indiscutiblemente era reacio a cualquier tipo de iglesia.

Si bien puede comprenderse el sentido y la validez de algunas de las críticas de García contra la esclerosis que se produjo en ciertas interpretaciones de la dialéctica y en particular por parte de algunas variantes del amplio espectro de lo que puede llamarse la tradición marxista, el error principal, a nuestro juicio, del pensador colombiano consistió en extrapolar tal petrificación de la dialéctica de modo concluyente al marxismo en su generalidad, sin diferenciar adecuadamente las distintas posiciones que se han producido en su nombre.

Tal reducción de la amplia, rica y profunda tradición del pensamiento marxista a una de sus formas particulares gestadas en la controvertida y enjuiciable época del stalinismo, en la que el Estado adquirió proporciones jamás imaginadas, ni por el propio Marx, por determinadas razones históricas que no es necesario analizar aquí, le condujeron a plantear:

Mi conclusión - todo lo limitada que se quiera, pero fundamentada en una investigación sobre los resultados del pensamiento histórico- es la de que el marxismo, impulsado por sus propias contradicciones internas (las de principio y las de aplicación) ha dejado de ser una filosofía dialéctica aplicada a la historia, convirtiéndose en una nueva escolástica. La dialéctica de la lucha ha ido cerrando e impermeabilizando los conceptos: quien pelea por la abolición del Estado ya no está dispuesto a estudiar críticamente las transformaciones históricas del Estado mismo, porque ha dejado de situar el vértice de la historia en la historia misma, para traspasarlo, insensible pero inevitablemente, a su propia conciencia, a su yo espectador beligerante de la historia (García, 2006, pp. 20-21).

De tal modo la genuina intención del pensador colombiano era rescatar la dialéctica de sus detractores exógenos y endógenos, pero lamentablemente en esta panóptica mirada del marxismo en relación con la dialéctica no 
siempre el bosque le permitió apreciar bien las diferencias y especificidades de cada uno de sus árboles.

Ahora bien, en este intento por presentar la luminosidad de las ideas de García respecto a este problema medular de la dialéctica como es su revelación real en la historia, por supuesto que, sin ignorar los imprescindibles lados oscuros que hay en su pensamiento - como sucede siempre en los más brillantes pensadores de la historia que no escapan a la creatividad epistemológica contenida también en los errores- la principal tarea del lector será orientarse por la claridad destellante de sus principales formulaciones teóricas, para tropezar solamente con los obstáculos que se presentan al aporte del nuevo saber creado por este intelectual colombiano en lugar de considerar su tarea satisfecha con regodearse en la detección de posibles errores de dicho autor.

No debe irse a buscar en las páginas de este libro definiciones estériles y congeladas sino el cálido y perenne replanteo teórico de categorías, argumentaciones, tesis, entre otras, que demandan constante reelaboración.

El libro se convierte en una especie de taller en el que se invita al lector a apropiarse de sus propias herramientas para salir de él con un objeto propio construido por él mismo en diálogo crítico, como lo ha exigido siempre la dialéctica desde su génesis etimológica, con el autor, quien con socrática sabiduría genera la duda en lector y despliega la mayéutica como el experimentado maestro que logra hacer cómplice a su discípulo, incluso de la necesaria superación de sus relativas verdades. Y en ese proceso deconstructivo aporta elementos para perfeccionar la propia herramienta básica del análisis que es la dialéctica misma. Diferenciando adecuadamente que "no toda negación contiene, en sí, todos los elementos positivos de la superación” (García, 2006, p. 19), va perfilando aristas cada vez más agudas al instrumental teórico de la dialéctica.

Esta obra, de García, puede en cierto modo considerarse preescrita tácitamente en algunos de sus otros enriquecedores estudios sobre las políticas coloniales, neocoloniales e imperialistas, el anquilosamiento de las estructuras oligárquicas, los procesos económicos y políticos emancipadores exitosos y fracasados en América Latina, las diferentes experiencias de la reforma agraria, las luchas políticas de movimientos étnicos y sociales y de líderes como Gaitán, las crisis de las instituciones políticas y educativas, y en general las convulsas historias de los pueblos latinoamericanos. De otro modo no se explica 
que pudiera desarrollar las elaboraciones teóricas de profundidad filosófica que atesora este ensayo. En él se pretende y en cierto modo se logra sintetizar de modo magistral la mirada analítica que observó, explicó y se planteó predecir algunos de los rumbos posibles no solo de los países latinoamericanos, sino también de los del capitalismo desarrollado y los del entonces existente campo socialista.

García no pudo, dada su muerte ocurrida en 1982, observar las transformaciones que se produjeron en este último a partir del despliegue de la perestroika y el desbarajuste producido por el desplome del Muro de Berlín, cuya polvareda aún mantiene nublada la mirada y no permite apreciar con claridad si realmente todos y cada uno de los pilares de aquellas sociedad se vinieron abajo o aún quedan algunos truncados sobre los cuales se intenta reconstruir el sabio capitalismo, cuyo mérito principal ha consistido en saber superar o en todo caso escamotear sus frecuentes crisis.

De otro modo, no puede explicarse la magistralidad con la cual Antonio García intenta y alcanza a perfilar a "La dialéctica como una filosofía de unidad en la historia" como denomina al tercer capítulo de su brillante ensayo en el que de manera analítica descompone el tema en varios epígrafes y subepígrafes como lo demandaría el exigente rigor académico que lo caracterizó, pero en verdad subyace el deseo de abordar los rasgos esenciales que caracterizan el método dialéctico en su expresión histórica, la personalidad de cada época histórica, la distinción entre los distintos tipos de materialismos y un panorama crítico de los principales momentos de la evolución filosófica referida a la interpretación dialéctica de la historia, especialmente en su tradición marxista.

Muchos serían los aspectos a destacar en esta parte final del libro que nos obligan a un pormenorizado análisis posterior de esta arista filosófica del pensamiento de García, pero no debe por el momento pasarse por alto algunas ideas sustanciales que el mismo se encarga de subrayar.

Entre todas ellas destacan tres tesis principales: "El método dialéctico concibe la historia como un proceso, con unas leyes de causalidad" (García, 2006, p. 22). De manera que a su juicio esto implica de algún modo la asunción del determinismo y la visión racional del mundo, distanciada de cualquier tipo de voluntarismo, vitalismo o irracionalismo e general.

El método dialéctico toma las perspectivas que la propia historia le da, ya que si bien sus resultados deben servir para algo —el estímulo de la lucha de 
clases y el arrasamiento de la sociedad capitalista para el marxismo comunista-, la necesidad política de unos resultados no debe imponer el unilateralismo de una sola perspectiva o de una perspectiva dominante: el activismo de la filosofía dialéctica marxista - en abierto contraste con el quietismo contemplativo de las filosofías idealistas, incluyendo la propia filosofía hegeliana- ha provocado la propia negación del método, haciendo primar, el fin político de las luchas del proletariado sobre la necesidad de una determinación objetiva de las leyes de transformación de una sociedad. El activismo ha anulado dialécticamente el método, al atarlo a la necesidad de unos resultados y de unas conveniencias políticas. Con razón ha dicho Kautsky que el marxismo no se impuso por su importancia teórica, sino por su papel en la lucha revolucionaria" (García, 2006, p.22).

Tesis esta que resulta muy polémica no por su premisa de partida, la cual resulta plenamente sostenible y en ese aspecto se fundamenta la concepción de García y de innumerables autores, que reconocen que la dialéctica no es una festinada invención especulativa -otra cosa es lo que en determinadas interpretaciones se ha intentado hacer con ella-, sino que es el producto sintetizado teóricamente del desarrollo histórico real. De ahí el acertado título de este libro.

A la vez insiste, también con suficiente razón, en el valor práctico de la dialéctica, cuando esta se utiliza adecuadamente en el proceso de la praxis sociopolítica y puede constituir un instrumento de orientación para la acción. Pero otra cuestión es aceptar las ideas según la cual "el activismo de la filosofía dialéctica marxista, ha provocado la propia negación del método". Así de manera generalizadora y sin tomar en adecuada consideración la amplia, diversa e incluso controvertida tradición del pensamiento marxista, hiperboliza el pragmatismo que limitó en ocasiones algunas posturas de discípulos, presuntamente ortodoxos del marxismo y desconoce otras posturas que mantuvieron y mantiene aún hoy viva la llama del forjador espíritu dialéctico que explican por qué razón a pesar del descalabro de la praxis de ciertos modos de concebir y tratar de edificar el socialismo su pretensión de utopía concreta no ha desparecido del horizonte humano.

Incluso en tiempos recientes de efervescencia política latinoamericana cuando gobiernos de izquierda se establecieron en la región como producto de la voluntad popular expresada en las urnas y aparecieron nuevos candidatos favorecidos también por esas orientaciones ideológicas contemporáneas pareciera que 
la dialéctica se expresara caprichosamente en una especie de primera negación del "socialismo real" por el "capitalismo real". Este a su vez pareció comenzar a ser negado no propiamente por el "comunismo real" (García, 2006, p. 50) ${ }^{152}$, sino por el "socialismo humanista", el "nuevo socialismo" (García, 1952, p. 33), ${ }^{153}$ o el "humanismo militante", como indistintamente les denominó.

152 “A dónde va el comunismo? Nadie podría responderlo, pero en ningún caso a la sociedad comunista. Los medios, la dinámica de los medios, han resultado más poderoso que la dinámica y la "fuerza irresistible" de los fines. El comunismo tendrá que aprender, en su propia historia, en qué consiste el proceso dialéctico de la negación de la negación".Idem. p. 50.

153 En el trabajo que denominó El Socialismo del siglo XXI, pero que inmediatamente subtituló de dos formas: "El Nuevo Socialismo un Humanismo Militante" y a renglón seguido "El sentido humanista del Nuevo Socialismo esboza una clara idea de lo que él desearía fuese ese tipo de sociedad tan añorada por múltiples generaciones de diversos pueblos del mundo. Esta es, en síntesis su idea del socialismo, que en otros trabajos tiene amplio desarrollo y que exigirá siempre de algún modo volver sobre el ideario sociopolítico y filosófico de este enjundioso pensador colombiano: “. El nuevo socialismo es filosóficamente dialéctico, pero ni idealista ni materialista; preconiza la tesis de la "socialización de los sectores vitales", pero no se deja arrastrar por la creencia de que todo el problema de la economía radica en una simple sustitución de la propiedad privada por la propia colectiva, admitiendo la coexistencia de las más diversas formas de propiedad; sienta que el problema no está sólo en una transformación del régimen de propiedad, sino en un tratamiento económico que garantice la previsión racional y la elevación de los niveles de bienestar y seguridad de todos los hombres; admite que la planificación es la forma más adecuada de socializar la dirección económica y de fijar la función social de la propiedad; cree en la necesidad de utilizar las grandes conquistas institucionales como el crédito, el dinero, los precios, etc.; piensa que es necio hablar de una abolición del Estado como método para eliminar la subordinación de clase, porque ni puede renunciarse a una de las más grandes adquisiciones históricas, ni es cierto que el Estado sólo pueda existir como órgano de opresión de clase; considera que el fin de la economía socialista y de una nueva organización de la sociedad no es sólo el de garantizar el bienestar y la seguridad, sino también la libertad, en todas las esferas de la vida humana; no acepta como medio la dictadura ni el predominio despótico del proletariado, frente a la dictadura dinástica y corruptora de la burguesía. Si el nuevo socialismo se llama substituto del comunismo - quizá el único verdadero substituto- es porque no sólo lo niega ideológicamente, sino por que representa una superación suya. Su colectivismo no es rígido sino funcional, porque ni intenta convertir en propiedad común todo lo que toca, ni desconoce que toda sociedad está hecha de hombres, ni admite el divorcio entre los dos términos indisolubles de la función: sociedad-individuo. Dice que la comunidad no es un bloque de cemento armado en el que desaparece la persona humana, el yo individual, la conciencia de cada uno, - como lo creen los comunistas - ni una "polvareda de hombres" o una acumulación de arena en la que el todo no representa nada orgánico ni sustanti- 
En años recientes en foros sociales y en gobiernos populares comenzaría a plantearse y realizarse experimentos de que un socialismo de nuevo tipo emerge en el siglo xxI, como vaticinara Antonio García. Otra cuestión es que recientemente la ofensiva neoliberal con métodos demagógicos ha recuperado fuerza en algunos gobiernos latinoamericanos. Esperemos cual será el desenlace de las medidas antipopulares que se están imponiendo en la actualidad.

Para Antonio García, "El método dialéctico le atribuye a la historia un sentido, sacado de ella misma, enfrentándose a quienes le niegan todo sentido a la historia y a quienes le atribuyen un sentido metafísico -religioso-, originado fuera del hombre". Tal vez sea esta una de las aseveraciones más sustanciales en lo que pudiéramos llamar los principios básicos de la interpretación de la historia promulgada por el pensador colombiano. Sostener en tiempos como los que fundamentalmente al final de su vida observó, cuando los pilares del marxismo se resquebrajaban producto entre otras causas de la obstinación dogmática de algunos de sus seguidores, y aparecían en el horizonte vientos postestructuralistas y posmodernistas que cuestionaban no solo el progreso y el humanismo como "metarelatos", sino la posibilidad de admitir algún tipo de sentido, al menos el plano retrospectivo, de la historia, podía parecer bien demasiado ingenuo cuando en verdad era todo lo contrario. Admitir la existencia de determinadas formas de sentido en la historia constituía no un volver atrás sino por el contrario intentar dar un paso más adelante incluso que los trasnochados posmodernistas y vaticinar el advenimiento de una nueva y necesaria época post-postmodernista, del mismo modo que añoró algo que ahora ya se dibuja para los ojos más aguzados: una nueva época postneoliberal, de verdadera integración latinoamericana y de solidaridad entre los pueblos del mundo.

Por último, es necesario resaltar que el análisis de Antonio García sobre el significado y el valor del método dialéctico resultaba iconoclasta en su mejor sentido de cuestionarse el posible sentido personalista que pudiera

vo, como lo creen los liberales. Su doctrina es siempre de síntesis, pero síntesis no significa promedio, acomodación simple de contrarios, sino superación de los términos en conflicto: "García, A. El cristianismo en la teoría y la práctica. Fondo de Publicaciones Vicente Azuero. 1952. Bogotá. 1952. p. 33. 
atribuirse a la elaboración del mismo, conclusión esta que, por supuesto, se aplicaba ante todo a sí mismo.

Según él: "Ni el método dialéctico, ni cualquier sistema de ideas, puede comprenderse como una absoluta creación personal, sino como un proceso: por eso mismo cometeríamos el más grave error si tomáramos ese método y esas ideas nada más que en su última manifestación -cuando la teoría aparece con una plena elaboración formal- y no rastreáramos en su doble línea de relaciones el tipo de sociedad, la dinámica creada por la influencia recíproca de factores sociales, la problemática de cada época histórica, de una parte; de otra, los sistemas troncales de ideas y sus adquisiciones metodológicas" (García, 2006, p. 32).

De tal modo, esta formulación constituía una invitación dirigida al lector para transmitirle la convicción que él ya poseía, según la cual, no habían personas predestinadas para enriquecer la teoría, el método dialéctico, la filosofía, la ciencia, u otras, sino que todo aquel que asumiera esa tarea con la entereza necesaria y un mínimo de condiciones básicas podía hacerlo, como él mismo lo hizo desde su Colombia natal o durante el periplo profesional que realizó por varios países latinoamericanos entre ellos Perú, Ecuador, Bolivia, Chile, República Dominicana y México, como asesor, consultor, investigador, profesor, entre otros.

En esa reconocida labor se destacó no solo por su talento y aporte intelectual, sino ante todo por su intención y gestión práctica con el afán de transformar las retrasadas estructuras socioeconómicas, políticas y culturales latinoamericanas. Por eso con acierto consideraba que "Dialécticamente, todo sistema de ideas es un efecto y una causa: como efecto, se relaciona con un tipo de sociedad -con una dinámica, unos problemas, unas exigencias, un estilo- y con un sistema o unas corrientes de ideas; como causa, se relaciona con los movimientos que determina en la historia, operando sobre ella -más o menos enérgicamente- a través de los múltiples canales de la acción política, religiosa, moral, estética o de cualquier otro orden" (García, 2006, p. 32). A esa acción política consagraría simultáneamente con su labor intelectual su infatigable vida, como infatigable crítico de la injusticia y el desorden social imperante, ${ }^{154}$ asesorando sindicatos, creando el partido

154 "Uno de los sistemáticos y permanentes leitmotiv de Antonio García, a través de su enorme trabajo como pensador social y prolífico escritor, se encuentra en la denun- 
socialista, promoviendo la creación de instituciones universitarias, gestando leyes y acuerdos favorables a los intereses de los sectores populares del país, solidarizándose con luchas obreras, campesinas, indígenas, estudiantiles y los procesos de descolonización que se efectuaban en el mundo con una consolidada postura antiimperialista.

El optimismo epistemológico que lo embargó y que ha sido común a lo mejor de la tradición humanista y desalienadora del pensamiento latinoamericano (Guadarrama, 2001), le hacía confiar a Antonio García en la superación de aquellos obstáculos que habían impedido que la comprensión dialéctica de la historia forjara bases terrenales con ayuda del realismo en lugar de construir apriorísticos esquemas sociales tanto desde el idealismo como del materialismo metafísico, del cual no escapaban algunas interpretaciones del marxismo. Tal vez sin proponérselo al desear salvaguardar y desarrollar la dialéctica, el destacado pensador colombiano estaría contribuyendo inconscientemente a rescatar el espíritu originario de la obra de Marx.

Estamos en presencia, sin dudas, en el ámbito latinoamericano de uno de los análisis que más aportó al enriquecimiento de la dialéctica y de la concepción materialista de la historia ${ }^{155}$ con independencia de que algunos puedan dudar de la condición de marxista en el caso de Antonio García. En definitiva parece muy apropiada para esta situación aquella idea de Lenin según la cual los filósofos no deben ser considerados ni clasificados por las etiquetas que ostentan sino por los problemas teóricos que resuelven.

cia durante casi medio siglo, de la crisis del orden tradicional, o mejor, del desorden tradicional". Rugeles, C. y L.E. Valencia. "Antonio García, el proceso histórico colombiano y la revolución social inconclusa” en Politeia. Revista de la Facultad de Derecho, Ciencias Políticas y Sociales. Universidad Nacional de Colombia. No. 22. Bogotá. 1994. p. 78.

155 "No faltan razones para llevar a Fernando Santacruz a pensar que: “'A nuestro juicio, El realismo dialéctico en la historia -La Crisis del Marxismo como Filosofía Histórica-, constituye el culmen del pensamiento filosófico elaborado por el Profesor García -durante el lapso de cuatro decenios-, la síntesis dialéctica en la que fundamenta toda su producción intelectual y, sin lugar a dudas, su gran aporte a la filosofía universal y a las ciencias políticas y sociales -particularmente la historia”. Santacruz, F. Círculo de Estudios Económicos Sociales "Antonio García” Bogotá. p. 66. 
Con la publicación de este trabajo, las nuevas generaciones intelectuales no solo latinoamericanas, sino de cualquier latitud donde pulse la intención de perfeccionar el pensamiento humano para que sea cada vez instrumento eficaz de transformación del mundo en que vivimos, tendrán la oportunidad de justipreciar por sí mismos, si fue aportativo o no a la teoría y por tanto a la práctica, este ensayo del prolífico y profundo pensador colombiano. 

Capítulo X

BIBLIOTECA

(NE COLOMBIANA 
